\title{
Estratégias de enfrentamento dos dilemas bioéticos gerados pela violência na escola
}

\author{
I ${ }^{1}$ Flavia Pedro dos Anjos Santos, ${ }^{2}$ Lícia Marques Vidal, ${ }^{3}$ Isaiane Santos \\ Bittencourt, ${ }^{4}$ Rita Narriman Silva de Oliveira Boery, ${ }^{5}$ Edite Lago da Silva Sena I
}

Resumo: A violência na escola é um problema social que perpassa o âmbito da educação e da saúde pública, envolve aspectos bioéticos e requer mecanismos de enfrentamento, a partir da educação em saúde. Este estudo objetiva discutir estratégias fundamentadoras da educação em saúde, sobre aspectos bioéticos no domínio da violência escolar. Consiste em uma revisão bibliográfica crítico-reflexiva por meio do acesso a banco de dados da Biblioteca Virtual de Saúde (BVS), utilizando os descritores "violência and bioética" e "violência na escola", considerando os estudos publicados no período de 2004 a 2009. Realizamos também levantamento das obras de Paulo Freire e Pedro Demo, teóricos da Educação Libertadora. A leitura do material conduziu-nos a definição e discussão de três eixos temáticos: 1) bioética como instrumento reflexivo para a retomada dos valores morais na sociedade; 2) escola como formadora ética e de exercício de cidadania; 3) educação em saúde como instrumento para o enfrentamento da violência na escola. Acreditamos que a violência escolar envolve questões bioéticas que devem ser alvo de intervenções educativas na perspectiva libertadora, no intuito de gerar reflexões sobre o caráter negativo da violência escolar, tanto para o ensino-aprendizagem, como para o adoecimento dos atores envolvidos nessa problemática. Os profissionais da saúde poderão estabelecer a intersetorialidade com a educação e contribuir na prevenção da violência na escola, por meio de ações educativas em saúde, mobilizando cidadãos para uma sociedade comprometida em promover a vida; e que os profissionais da educação sejam receptivos e coparticipantes do processo intersetorial de educação e saúde.

\author{
1 Enfermeira, docente da \\ Universidade Estadual do \\ Sudoeste da Bahia (UESB), \\ mestranda do Programa de \\ Pós-Graduação em Enfermagem \\ e Saúde (PPGES) - UESB. \\ 2 Enfermeira, mestranda do \\ PPPGES-UESB. \\ ${ }^{3}$ Enfermeira, mestranda do \\ PPGES-UESB. \\ ${ }^{4}$ Enfermeira, doutora e docente \\ do PPGES-UESB. Endereço \\ eletrônico: rboery@gmail.com. \\ ${ }^{5}$ Enfermeira, doutora e docente \\ do PPGES-UESB.
}




\section{Introdução}

Este artigo aborda a Educação em Saúde como estratégia de enfrentamento dos dilemas bioéticos da violência na escola. A violência é uma temática bastante complexa e abrangente, pauta de discussões e preocupações no Brasil e em vários países, nos quais a repercussão de suas consequências nas famílias, especialmente entre adolescentes e jovens, têm atingindo a sociedade de um modo geral, levando estudiosos e pesquisadores à exploração do tema em busca da identificação de sua multicausalidade e possíveis mecanismos de enfrentamento (MINAYO, 2007).

A violência, que sempre foi visualizada sob a ótica da segurança pública, da educação e como uma questão do âmbito social, atualmente tem sido apontada como um grave problema da saúde pública, responsável pela morte de 1,6 milhões de pessoas a cada ano, segundo relatório da Organização Mundial de Saúde (OMS) do ano de 2002, principalmente entre 15 e 44 anos de idade. A OMS assinala que a sociedade convive com a violência desde sempre, mas não deve aceitá-la como um aspecto inevitável da condição humana. Faz-se necessário encontrar meios de preveni-la ou ao menos limitá-la. Até então, os profissionais de saúde envolviamse apenas com suas consequências, mas a abrangência da temática impõe maior empenho desses profissionais em viabilizar formas de solução para o problema. Este é o primeiro relato da OMS conceituando a violência como um problema de Saúde Pública (OPS, 2002).

Ao lado da violência, sempre houve sistemas estruturados em busca de mecanismos de enfrentamento, tais como religiosos, filosóficos, legais e comunitários. Não foram completamente suficientes, mas deram suas contribuições (DALHBERG; KRUG, 2007). Atualmente surge a possibilidade de minimização do problema da violência por intermédio da Educação em Saúde, considerando a força que tendências pedagógicas libertadoras têm demonstrado para a transformação da práxis.

As manifestações dos atos violentos vão desde homicídios, suicídios, agressōes, ameaças e também violência contra patrimônio (MINAYO, 2007). Estudos apontam que, no ambiente escolar, os atos violentos mais comuns são depredaçōes e invasões dos prédios; agressões físicas e verbais envolvendo alunos, professores e funcionários das escolas; rivalidades, ameaças - tudo isto com forte 
influência do tráfico de drogas (principalmente em periferias), determinação de espaços de poder e banalização da violência (SISTO, 2005).

Neste estudo, especificamente, referimo-nos à violência que ocorre no âmbito escolar, não necessariamente a que envolve um agente agressor externo (uma "gangue" ou traficantes que vieram "acertar contas" com algum discente, ou o companheiro de uma docente que veio à escola enfurecida). Referimo-nos à violência na escola envolvendo discentes e docentes, que fragiliza a relação e macula o ambiente com práticas inaceitáveis e inadequadas, promovendo permissividade, quebra de autonomia (do docente) e fragilização do respeito.

Considera-se que a violência na escola perpassa por questôes bioéticas, tendo em vista que a bioética se ocupa do resgate da humanização das relações humanas e que o jovem e o adolescente enfrentam grande instabilidade ao iniciar a construção de suas habilidades intelectuais, afetivas e sociais, tão necessárias a sua integração na comunidade adulta com autonomia, maturidade e independência. Os valores morais, éticos e sociais estão embaçados na visão do jovem/adolescente, que se encontra confuso em meio às desigualdades sociais experienciadas, os conflitos da idade, a busca por uma realização pessoal e as muitas impossibilidades, situação que gera sentimentos ambivalentes e a desorganização da malha social, culminando com tensão emocional, estresse e violência (GRANGE et al., 2006).

Não há elementos suficientes para lidar com a dimensão da problemática, mas estudos interdisciplinares, como propõem Negrão; Guimarães (2004), elucidam possíveis alternativas e trazem a compreensão de questôes com as quais a violência possa ter alguma interface. Daí, encontraremos o entrelaçar da Pedagogia, Psicologia, Sociologia - enfim, das ciências humanas e sociais de uma forma geral - imbricadas e comprometidas com a sistematização e compreensão do fenômeno violência na escola. Vislumbramos, então, a parceria viável entre a educação e a saúde somando esforços no intuito de permeabilizar a temática e encontrar subsídios para seu enfrentamento.

Diante da problemática, ocorreu-nos a questão: que estratégias de educação em saúde poderão ser utilizadas na discussão dos aspectos bioéticos que permeiam a violência na escola? Para responder à questão, estabelecemos como objetivo: discutir estratégias que fundamentam a educação em saúde, sobre aspectos bioéticos, no domínio da violência na escola. 


\section{Método}

Trata-se de uma revisão bibliográfica, crítico-reflexiva, por meio do acesso a banco de dados da Biblioteca Virtual da Saúde (BVS), entrando com os descritores "violência and bioética" e "violência na escola", nos meses de maio e junho de 2009, considerando os estudos publicados no período de 2004 a 2009. Realizamos também um levantamento nos Parâmetros Curriculares Nacionais e nas obras de Paulo Freire e Pedro Demo, teóricos clássicos da Educação Libertadora, das quais selecionamos duas obras de cada autor. $\mathrm{Na}$ busca eletrônica foram encontrados 142 estudos, dos quais oito foram selecionados, por serem mais propícios ao alcance do objetivo. A leitura do material conduziu-nos à definição e discussão de três eixos temáticos, a saber: 1) a bioética como instrumento reflexivo para a retomada dos valores morais na sociedade; 2) a escola como formadora ética e de exercício de cidadania; 3) a educação em saúde como contribuinte ao enfrentamento da violência na escola.

\section{Resultado e discussão}

\section{A Bioética como instrumento reflexivo para a retomada dos valores morais na sociedade}

A sociedade contemporânea, fruto de uma série de modificações histórico-sociais, possui em sua estrutura diferentes legados que permite na sua definição perceber as ambiguidades e dicotomias inseridas no cotidiano social. Tendo em vista o contexto brasileiro de organização, pode-se compreender que características como concentração de renda, elevado índice de analfabetismo, desigualdade social, sistemas públicos de saúde, educação e apoio social insuficientes para sanar as necessidades da população propiciam uma organização da sociedade fragilizada no tocante aos aspectos éticos - haja vista que os preceitos da ética e moral são construídos e edificados no perpassar das relações humanas (GRANGE, 2006).

O ambiente relacional da sociedade contemporânea envolve determinantes sociais, muitas vezes distantes dos valores éticos e morais, estimuladores da reflexão e criticidade. Neste sentido, torna-se necessário conceituar os termos "ética" e "moral", tendo em vista a proximidade de significado entre eles, além da possibilidade de contribuir para a concepção da bioética como instrumento reflexivo. Segundo Cohen; Gobbetti (2004), o ser humano possui uma capacidade para a eticidade, podendo, no decorrer da vida, desenvolver ou 
não a ética. Logo, os homens não nascem éticos, mas podem desenvolver esta habilidade em um processo de aprendizagem.

Assim, a ética pode ser compreendida como uma norma ou regra construída e determinada por grupos sociais, com a finalidade de traçar um equilíbrio de ações baseada em uma vertente instituída, possuindo como características a autonomia, consciência e coerência, que permitem a flexibilidade de ação frente às situações cotidianas, o que contribui para a elaboração de condutas éticas frente à capacidade de articular conhecimento (razão) à sensibilidade de percepção (emoção), atingindo dessa maneira as naturezas da essência do homem, que envolvem o biológico e o psicossocial. A ética envolve a essência da humanidade ao abordar o modo de ser do homem, presente nas relaçôes do ser humano com seu próprio ser e com a sociedade a sua volta (COHEN; GOBBETTI, 2004).

De maneira complementar, a moral pode ser definida etimologicamente com grande proximidade da ética; entretanto, alguns estudiosos definem que a tênue diferenciação desses conceitos se apresenta no aspecto cultural, ao considerar que a moral permite aos sujeitos que guiem suas ações respaldadas na herança geracional da sociedade, traduzida pela cultura. Além de fundamentar-se em bases distintas da ética, como incontestabilidade dos valores pré-estabelecidos, a definição dos conceitos certos e errados que nortearam as condutas são impostas socialmente, e a transgressão a esses valores pressupõem punição (COHEN; GOBBETTI, 2004).

Logo, a compreensão das concepções de ética e moral envolve subsídio para um novo olhar nas questôes sociais que perpassam os valores e atitudes do homem inserido em sociedade. Além disso, essa compreensão colabora para o entendimento da bioética como ciência que, na área da saúde, estabelece contribuições para a construção de instrumentos de mediação de conflitos. Conforme afirmam Cohen; Gobbetti (2004), a bioética define-se como a ética das relaçôes que permite estratégias para lidar com a dualidade da vida, onde o certo e errado muitas vezes se confundem, sendo imprescindível ter sensibilidade e criticidade para perceber o contexto que envolve a situação e contribuir para a reflexão de caminhos acerca da utilização do conhecimento.

Outro aspecto da bioética que merece discussão refere-se à definição de autonomia, onde o ser humano, no ambiente bioético, reconhece seu espaço de liberdade para decisões ao também conceber o espaço do outro, sendo a autonomia limitada à medida que os conceitos do direito individual se 
confrontam à perspectiva do direito coletivo. E, nessa situação, qual deve prevalecer? As respostas predeterminadas não compõem a proposta da bioética, mas a complexidade do evento e a reflexão pautada na ética norteiam uma decisão mais acertada, sendo o respeito a si e ao outro, uma estratégia para a condução das divergências (COHEN; GOBBETTI, 2004).

Diante de tantos desafios da sociedade contemporânea, a bioética possui uma importante contribuição para a retomada dos valores morais. Ao possibilitar diretrizes que permitam construir uma formação de cidadãos éticos e comprometidos com a sociedade, sendo o respeito a base para a compreensão da dinâmica social (COHEN; GOBBETTI, 2004). As diversidades organizacionais e sociais presentes na sociedade propiciam na bioética o encontro com dilemas que requerem um enfrentamento permeado de reflexões e pautado no respeito para maior discernimento. Nesta conjuntura, a compreensão do conceito da bioética transcende a esfera etimológica e possibilita à sociedade a compreensão de uma nova perspectiva de atuação, que envolve o sujeito como agente ético e responsável pelos rumos da sociedade, como organização social.

Após conceituar os elementos, ética, moral e bioética, articulados à realidade da sociedade moderna, uma reflexão acerca do papel, em especial da bioética, neste aspecto faz-se necessária. Como definido anteriormente, a eticidade do ser humano, base para a atuação ética, desenvolve-se à medida que o homem toma consciência do seu ser, sendo fundamental neste processo a tomada de consciência que envolva “o se conhecer" para compreender o universo a sua volta (COHEN; GOBBETTI, 2004).

O homem pode contribuir eticamente ao construir, no processo de aprendizagem, habilidades que envolvam o conhecimento e a sensibilidade, para lidar com as dualidades que a vida em sociedade propõe. Neste ponto, um questionamento emerge: como contribuir para uma retomada de valores na sociedade atual, sendo que a descrença em atuações éticas é uma constante?

Na perspectiva de sugerir alguns aspectos para reflexão, e tendo como fundo que a ética possui diversas possibilidades de atuação, a resposta deste questionamento envolve a percepção fundamental que a sociedade tem, de compreender que o campo das relações humanas permite a descoberta e convivência com situações mútuas, que possibilitam o atuar ético ou não do ser humano. A diferença nesta atuação é desenvolvida no processo de formação, onde o estabelecimento de 
vínculos, a convivência familiar, as experiências de convivência com o outro são elementos influenciadores deste processo (COHEN; GOBBETTI, 2004).

Vale ressaltar que as definições aqui citadas visam a contribuir para a reflexão, sem, contudo, definir pontualmente que não existem outras possibilidades, ao compreender a ética conjuntamente com a bioética, como ciência que possui uma complexidade de atuação, em que cada situação deverá ser analisada e avaliada, para as especificidades, na tomada de decisão.

\section{A Escola como formadora ética e de exercício de cidadania}

A violência é um problema sócio-histórico tão antigo quanto a humanidade, mas nas últimas décadas vem ganhando espaços cada vez maiores nos meios de comunicação, em estudos e pesquisas, suscitando novas reflexões diante de suas múltiplas manifestaçôes, tais como atos violentos contra patrimônios ou pessoas; agressões morais, verbais ou físicas; sejam nos domicílios ou nas vias e ambientes públicos, a exemplo das escolas. Configura-se também como um problema de segurança pública, de educação e de saúde. Embora este último demorasse um pouco mais a ser reconhecido, sabe-se que a violência afeta a saúde individual e coletiva, exigindo uma prevenção e enfrentamento, além da formulação de políticas específicas e organização de práticas e serviços próprios do setor saúde (MINAYO, 2007).

A presença da violência no contexto escolar, envolvendo discentes e docentes é inegavelmente reprovada, tendo em vista que a escola é o local na sociedade onde se deve apreender a disciplina. Constitui o santuário do conhecimento; a extensão do lar; o ambiente apropriado para a continuidade da formação do caráter do indivíduo; a condição fundamental para o crescimento pessoal, profissional e intelectual. E o docente representa a figura do educador, do mediador do conhecimento, aquele que, por participar efetivamente da vida do discente, merece, ou pelo menos deveria merecer, respeito e amabilidade.

Como a violência adentrou os portóes das escolas? Quem, o quê ou de que forma consentimos com sua permanência nas salas de aula e nos corredores, nas horas de intervalo? Não seria uma inversão de valores ou a ausência da revisão destes? Será que a violência, ao adentrar os portôes das escolas, fez com que os valores éticos perdessem espaço nos ambientes escolares? Ou tais valores se evadiram antes mesmo das primeiras manifestações violentas começarem a acontecer? 
Estes são alguns dos questionamentos que nos sobrevêm ao refletirmos sobre a temática e, quando nos referimos aos aspectos bioéticos, estamos falando da bioética da vida cotidiana, aquela relacionada aos comportamentos das pessoas e às idéias de cada um (EINAUDI, 1991). Este conceito extrapola a dimensão biomédica e possibilita-nos uma reflexão nova e ampliada sobre a violência no âmbito escolar, tendo em vista que a bioética se apresenta como um "instrumento reflexivo para resgatar a ponte entre o homem e seus valores morais" (GRANGE et al., 2006, p. 2).

Os aspectos bioéticos relacionados à violência na escola dizem respeito à violação dos direitos humanos em função da luta pelo poder e implica atos violentos, aproximando as ciências sociais e da saúde, a educação normativa e também as questões jurídicas (BRAZ, 2004). Falamos de questão jurídica pelo reconhecimento dos direitos humanos, incluindo o direito à saúde.

A bioética por muito tempo foi colocada à parte em relação à violência, porém, as relações humanas interespecíficas consistem em um grupo temático de interesse da bioética (EINAUDI, 1991) e a relação conflituosa discente-docente está incluída quando nos reportamos às notícias veiculadas acerca das agressões ocorridas, da violação dos direitos humanos, do amedrontamento gerado na escola pela intranquilidade da presença do discente-agressor e as repercussões trágicas dos acontecimentos envolvendo discente-docente-violência.

Sendo a violência um problema social e de saúde pública, tendo sua gênese, segundo alguns estudiosos da temática, no tecido social, cultural e econômico da vida humana (DAHLBERG; KRUG, 2007), ou nas questóes contextuais como pobreza, exclusão social, desemprego, fome, discriminação social; ou pessoais como biológicas e psicológicas (RISTUM; BASTOS, 2004), há de se considerar as dimensões bioéticas do fenômeno violência na escola.

Sabe-se que a desigualdade social existente no Brasil favorece a violência em suas mais diversas manifestaçôes. No entanto, no cenário da escola, este não é um fator determinante, uma vez que o fenômeno ocorre também em escolas de classe média e alta. Dessa forma, não deve ser percebida apenas nos aspectos desencadeantes, mas sim, ampliamos o nosso olhar, inserindo neste contexto a bioética, pois a violência diminui a qualidade de vida, faz adoecer e provoca mortes, proporcionando dilemas bioéticos, tais como a conduta do educador frente ao educando agressor; a interferência no processo ensino-aprendizagem, 
devido à quebra da autonomia e ruptura da confiança e respeito em sala de aula; o amedrontamento a que o agressor submete o educador na disputa de poder e autoridade (DIAS apud BRAZ, 2004).

Tais dilemas bioéticos no ambiente escolar levam educadores a incluírem nos currículos escolares temas mais voltados para a construção da cidadania, para a contribuição do adolescente e do jovem como construtores ativos de uma sociedade fortalecida, com condiçōes de enfrentar os dilemas e desafios propostos à juventude (GRANGE et al., 2006). Neste sentido, a educação entra como meio de favorecer a formação ética e cidadã dos discentes. Os Parâmetros Curriculares Nacionais (PCN) apontam como meta o estímulo à ética nas unidades escolares, sendo ela responsável pela construção e tomada de decisão consciente dos discentes, exercendo preponderante papel no exercício da cidadania. Sendo assim, a bioética na escola pode levar o educando a compreender a necessidade de um contínuo pensar, refletir e construir, o que favorece o exercício da cidadania a partir do momento que impulsiona a problematização constante do viver pessoal e coletivo (BRASIL, 1998).

Percebemos que a não-observação das questôes bioéticas constitui uma brecha que acaba sendo preenchida por relações desarmônicas entre os protagonistas do processo educativo que são os docentes e discentes, podendo resultar em situaçôes de agressão física, psíquica e moral. Entendemos que o processo educativo deve consistir numa prática flexível e democrática, que valorize o singular em meio à pluralidade encontrada nas diversas salas de aulas, por meio do diálogo, da participação e da transformação da atual realidade de desprestígio dos valores éticos na escola.

As situaçôes de violência que ocorrem no interior das escolas suscitam, em muitos casos, a presença de força policial, colocando em evidência a dificuldade dos docentes de exercer sua autoridade para resolver os conflitos, uma vez que ultrapassam a capacidade de resolução por parte dos docentes. As "briguinhas" entre colegas cederam espaço às graves agressóes físicas e verbais entre eles e entre discentes e docentes, muitas vezes com o porte de armas de diversos tipos. $\mathrm{O}$ que estamos presenciando hoje é fruto de um quadro que ainda não foi devidamente compreendido. Uma profunda crise de identidade da instituição escolar e, por consequência, dos atributos existentes na relação docente-discente (RISTUM; BASTOS, 2004). 
Parece-nos que a banalização da violência no espaço escolar tem inibido o caráter transformador tão necessário à sociedade, uma vez que incide sobre a qualidade do ambiente escolar, ferindo, há muito tempo, o processo ensinoaprendizagem, favorecendo a evasão e repetência, desestímulo no docente em exercer sua profissão, contribuindo, dessa forma, com o processo de aceleramento das desigualdades e iniquidades sociais. Surge então a educação em saúde como uma possibilidade de enfrentamento de dilemas bioéticos relacionados à violência no âmbito escolar.

\section{A Educação em Saúde como contribuinte ao enfrentamento da violência na escola}

O processo educativo passou por diversas mudanças no decorrer do tempo, e na atualidade representa um instrumento didático e pedagógico de transformação do ser humano, à medida que permite gerar conhecimentos sobre questôes bioéticas e humanas de valorização da vida e estímulo à cidadania. Tal processo tem sido marcado por interesses contraditórios, interações e sonhos do conjunto de sujeitos que está direta ou indiretamente envolvido na formação de cidadãos.

A escola, além de estar relacionada diretamente à construção de conhecimento, possui a responsabilidade e compromisso na construção de uma sociedade mais cidadã, haja vista que a educação é capaz de transformar e emancipar o indivíduo para escolhas críticas e reflexivas, levando-o a aprender a aprender, saber pensar, informar-se e refazer diariamente a informação, questionar (DEMO, 2002). Entretanto, na sociedade atual, deparamo-nos com situações de terror e medo nas escolas, onde os próprios discentes são sujeitos de atos violentos contra os docentes e colegas, dificultando o processo ensino-aprendizagem e reforçando fatores que interferem negativamente no processo saúde-doença. Nesta perspectiva, a educação em saúde pode contribuir para a construção de estratégias de enfrentamento da violência na escola, partindo da utilização de ações educativas que possam suscitar reflexões de discentes e docentes a partir dos pressupostos da Educação Libertadora.

Embora o discurso atual no domínio da educação enfatize a tendência libertadora, a prática pedagógica predominante nas escolas de nosso meio tem evidenciado a continuidade da transmissão de conhecimentos desarticulado da realidade social e da experiência de vida do discente. A tendência pedagógica 
libertadora estabelece o discente como centro do processo educacional, devendo ser considerado em seu contexto sociocultural com todas as particularidades de vida. Neste sentido, educar implica contribuir para a mudança na visão de mundo do ser humano a partir da interação e construção do conhecimento, corroborando a perspectiva freiriana que estabelece a concepção de educar para a decisão, para a responsabilidade social e política, trazendo à tona a contextualização do discente na educação como ator e não mais como sujeito (FREIRE, 2000).

Deste modo, a educação deve impulsionar a conquista da democracia que designa um modo de vida, em que cada indivíduo tem direito de participar livremente da definição e escolha dos valores sociais, políticos e civis, sendo parte intrínseca da construção de uma sociedade em que a participação do cidadão é fundamental. Além disso, a educação deve ser vista como direito social, constituindo-se historicamente um pré-requisito para a expansão dos outros direitos. Sem educação, a população não poderá participar ativamente do caminho a ser seguido em direção a uma sociedade mais equânime que viabilize a redução das desigualdades sociais (DEMO, 2001). Assim, devemos pensar nas estratégias de educação em saúde sob a perspectiva da participação social, uma vez que essas estratégias podem contribuir para a formação de atores sociais que constroem sua história, em direção ao desenvolvimento de relações de respeito, confiança, ajuda mútua e empatia.

Consideramos que os profissionais da área de saúde devem mobilizar a comunidade nos espaços intra e extraescolares, quanto a sua capacidade de propor soluções adequadas ao enfrentamento da violência que está se instalando no ambiente da escola, ou seja, levá-la a refletir sobre as implicações bioéticas que estão envolvidas nesse tipo de violência a partir da contextualização da problemática, o que significa refletir com os atores envolvidos, de modo que impulsione um esforço permanente por meio do qual eles percebam, criticamente, como estão sendo no mundo, com que e em que se acham (FREIRE, 2000).

Acreditamos que as estratégias de educação em saúde para enfrentar a problemática posta encontram na Educação Libertadora um forte embasamento teórico e pedagógico a ser delineado a partir das relações do homem com a realidade, que resultam de estar com ela e de estar nela, pelos atos de criação, recriação e decisão, por meio dos quais os diferentes atores podem se tornar os autores de suas escolhas e responsável por seus próprios caminhos, contribuindo 
com o jogo das relações do homem com o mundo e do homem com os homens, desafiado e respondendo ao desafio, alterando, criando, que não permite a imobilidade diante das situações com as quais se depara (FREIRE, 2000). Desse modo, para que se alcance êxito na elaboração de estratégias de educação em saúde, é necessário haver forte engajamento entre profissionais de saúde, comunidade e profissionais da educação, como expressão coletiva de suas intençôes, alicerçados na realidade onde se inserem, na perspectiva de desenvolver ações que possam prevenir e minimizar a violência nas escolas.

Diante do exposto, os profissionais de saúde, ao se aproximarem do cotidiano das escolas, estarão contribuindo com a intersetorialidade, que deve ocorrer entre os setores saúde e educação, e estarão também delineando estratégias condizentes com a realidade encontrada, uma vez que as situações de violência existentes na escola são fatores que interferem negativamente no processo saúde-doença das pessoas envolvidas direta ou indiretamente com a problemática.

$\mathrm{Na}$ área da saúde, os profissionais de saúde utilizam-se da educação em saúde como um instrumento de trabalho na construção da relação com os usuários dos serviços de saúde, à medida que a saúde perpassa todos os aspectos do viver humano e requer, para a transformação dos sujeitos, uma profunda interação entre o profissional de saúde e a população, com vistas a permeabilizar as condutas que gerem saberes.

\section{Reflexões finais}

Acreditamos que a violência escolar envolve implicações bioéticas que devem ser alvo de intervenções educativas fundamentadas na perspectiva da educação libertadora. Para tanto, devemos conhecer a realidade vivenciada por docentes e discentes, no intuito de gerar reflexóes sobre o caráter negativo da violência escolar, tanto no aspecto ensino-aprendizagem, quanto como um fator que contribui para o adoecimento das pessoas. Nesse sentido, é fundamental que haja a intersetorialidade entre a saúde e a educação e, a educação em saúde constitui-se como uma estratégia fundamental para a ocorrência desse processo, especialmente por meio de metodologias ativas como oficinas, debates, construção de cartilhas, dentre outros, com o objetivo de alertar e prevenir a violência no espaço escolar.

Sabemos que a educação em saúde é uma tarefa complexa, mas acreditamos ser viável e possível, desde que os profissionais de saúde a promovam com a finalidade 
de mobilizar cidadãos em direção a uma sociedade mais fraterna e comprometida na promoção da vida, e que os profissionais da educação sejam receptivos e coparticipantes desse processo intersetorial, envolvendo a educação e a saúde.

A violência na escola apresenta-se como um desafio para a sociedade contemporânea. Ao se relacionar com a área da saúde, despontam as perspectivas da educação em saúde como instrumento de transformação da sociedade, ao possibilitar o compartilhamento dos saberes.

\section{Referências}

BRASIL. Secretaria de Educação Fundamental. Parâmetros Curriculares Nacionais: terceiro e quarto ciclos. Apresentação dos temas transversais. Brasília: MEC-SEF, 1998, p. 436. Disponível em: <www.sinepe-sc.org.br/5a8tt.htm>. Acesso em: 15 abr 2009.

BRAZ, M. Bioética e Violência. Revista Bioética, Brasília, v. 12, n. 2, p. 77-98, 2004. Disponível em: <http://www.portalmedico.org.br/revista/bio12v2/simposios.pdf >. Acesso em: 17 jul.2009.

COHEN, C.; GOBBETTI, G. Bioética da vida cotidiana. Psicanálise. 2004. Disponível em: $<$ http://cienciaecultura.bvs.br/scielo.php?script=sci_arttext\&pid=S0009-672520040004 00020\&lng=en>. Acesso em: 16 mai. 2009.

DAHLBERG, L.L.; KRUG, E.G. Violência: um problema global de saúde pública. Ciência e Saúde Coletiva, v. 11, supl., p. 1163-1178, 2007. Disponível em: http://www.scielosp.org/ scielo.php?script=sci_arttext\&pid=S1413-81232006000500007>. Acesso em: 15 mai. 2009.

DEMO, P. Participação é conquista: noções de política social participativa. 5.Ed. São Paulo: Cortez, 2001.

DEMO, P. Desafios modernos da Educação. 12.ed. Petrópolis: Vozes, 2002.

EINAUDI, G. Bioética cotidiana e Bioética de situaçoes limites. In: Questioni di Vita: ética, scienza, salute. São Paulo: Hucitec, 1991.

FREIRE, P. Pedagogia do oprimido. 26.ed. Rio de Janeiro: Paz e Terra, 1987.

FREIRE, P. Educação como prática da liberdade. 24.ed. Rio de Janeiro: Paz e Terra, 2000.

GRANGE, L. ET al. Educação, violência e Bioética sob a ótica do estudante Secundário Brasileiro. Âmbito jurídico, p. 1-6, 2006. Disponível em: <http://www.ambito-juridico.com.br/ site/index.php?n_link=revista_artigos_leitura\&artigo_id=1233>. Acesso em: 18 jul. 2009. MINAYO, M.C. de S. A inclusão da violência na agenda da saúde: trajetória histórica. Ciência e Saúde Coletiva, v. 11, supl., p. 1259-1267, 2007. Disponível em: <http://www.scielo.br/ pdf/csc/v11s0/a15v11s0.pdf>. Acesso em: 18 jul. 2009. 
NEGRAO, A.V.G.; GUIMARAES, J.L. A Indisciplina e a Violência Escolar. 2004. Disponível em: <http://www.unesp.br/prograd//artigos/eixo7/aindisciplina>. Acesso em: 25 jun. 2009.

ORGANIZAÇAO PANAMERICANA DE SAÚDE. Informe Mundial sobre a Violência e a Saúde: resumo. Organização Mundial de Saúde. Washington, DC. 2002. Disponível em: <http://www.who.int/violence_injury_prevention/violence/world_report/en/>. Acesso em: 19 jul. 2009.

RISTUM, M.; BASTOS, A.C. deS. Violência urbana: uma análise de conceitos de professores do ensino fundamental. Ciência e Saúde Coletiva, v. 9, n. 1, p. 225-239, 2004. Disponível em: <http://www.scielo.br/scielo.php?script=sci_arttext\&pid=S1413-81232004000100022>. Acesso em: 15 mai. 2009.

SISTO, F.F. Aceitação-rejeição para estudar e agressividade na escola. Psicologia em Estudo, Maringá, v. 10, n.1, p. 117-125, 2005. Disponível em: <http://www.scielo.br/pdf/pe/v10n1/ v10n1a13.pdf>. Acesso em: 16 mai. 2009. 


\section{Coping strategies to bioethical dilemmas generated by school violence}

School violence is a social problem that pervades the educational and public health context, involving bioethical issues and requires coping mechanisms from health education. This study aims to discuss strategies that underlie health education, on bioethical issues in the school violence field. It consists of a critical-reflexive literature review by accessing the Virtual Health Library (VHL) database, using the keywords: "violence and bioethics", and "violence at school", considering the studies published from 2004 to 2009. We also surveyed Paulo Freire's and Pedro Demo's works, theorists of Libertarian Education, which led us define and discuss three thematic areas: 1 ) bioethics as a reflective instrument for the moral values resumption in the society, 2) school as an ethics and citizenship practice creator, 3) health education as a contributor to coping with violence at school. We believe that school violence involves bioethical issues that should be the target of educational interventions in the liberating perspective, in order to generate reflections on the negative character of school violence, both for teaching and learning, as to the sickening of the actors involved in this issue. Health professionals may establish the intersectoriality with the education and contribute in preventing violence at school, through health education actions, mobilizing citizens for a society committed to promoting life. And the education professionals must be receptive and co-participants in the education and health intersectorial process.

Key words: bioethical dilemmas, health education, violence at school, violence and health. 